\title{
Design, fabrication and characterization of high-performance AIGaN UV photodetectors
}

\author{
Ekmel Ozbay, Bilkent University, Bilkent, 06800 Ankara, Turkey \\ Tel.+90-312-290-1966, Fax.+90-312-290-1015, ozbay@bilkent.edu.tr
}

\begin{abstract}
AlGaN based photodetectors have emerged as an alternative to conventional ultraviolet (UV) sensors with the advent of metal organic chemical vapor deposition (MOCVD) systems [1-2-3]. Many workers have demonstrated metal-semiconductor-metal (MSM) [4- 5], Schottky [6], p-i-n [7] and avalanche type [8] AlGaN UV photodetectors successfully. Ultraviolet detectors have a wide range of applications in flame, fire and missile detection, chemical and biological analysis, short distance non-line- of-sight optical communications, as well as emitter calibration. The existing fire warning systems utilize infrared (IR)/IR [9], UV/IR, or UV/visible/IR channels. Multiband narrow-spectrum UV detectors would in turn increase the fire source and range recognition capabilities of such systems and help to eliminate false alarms. One method of narrow spectral-band detection is to employ absorptive epitaxial filter-layers [10].
\end{abstract}

The AlGaN p-i-n structures were grown on double-side polished c-plane sapphire ( $\left.\mathrm{Al}_{2} \mathrm{O}_{3}\right)$ substrates by 1 owpressure metal organic chemical vapor deposition (MOCVD) system, which is located at the Bilkent University Nanotechnology Research Center. First, the wafer surface was cleaned by desorption in an $\mathrm{H} \quad{ }_{2}$ environment at $1,080^{\circ} \mathrm{C}$. Then, a $\sim 100 \AA$ AlN nucleation layer was grown at $550^{\circ} \mathrm{C}$ by trimethylaluminum (TMAl) and ammonia $(\mathrm{NH} \quad 3)$ under 50mbar pressure. Subsequently, a high temperature $\left(1,135^{\circ} \mathrm{C}\right) \mathrm{Al} \quad{ }_{0.4} \mathrm{Ga}_{0.6} \mathrm{~N}$ buffer layer of $1,600 \AA$ was grown with trimethylgallium $(\mathrm{TMGa})$ and a high flow $\mathrm{NH} 3$ at $1,160^{\circ} \mathrm{C}$. An N-layer with a thickness of $5,000 \AA$ was grown with silane (SiH4), in turn resulting in a carrier concentration of $10{ }^{18} \mathrm{~cm}^{-3}$. The growth continued with a $6,000 \AA \mathrm{Al}_{0.4} \mathrm{Ga}_{0.6} \mathrm{~N}$ i-layer at $1,130^{\circ} \mathrm{C}$. In the last step, a $1,000 \AA \mathrm{Al} \quad{ }_{0.4} \mathrm{Ga}_{0.6} \mathrm{~N}$ p-layer with $\mathrm{Mg}$ doping by biscyclopentadienylmagnesium $\left(\mathrm{Cp}_{2} \mathrm{Mg}\right)$ was grown at $1,050^{\circ} \mathrm{C}$. In all of the steps, the carrier gas was $\mathrm{H}_{2}$ and the chamber pressure was kept at $50 \mathrm{mbar}$.

The samples were fabricated via a six-step microwave-compatible fabrication process in a class-100 clean room environment[11-12]. The dry etching was accomplished by reactive ion etching (RIE) under CCl ${ }_{2} \mathrm{~F}_{2}$ plasma, $20 \mathrm{sccm}$ gas flow rate, and $200 \mathrm{~W}$ RF power conditions. Mesa structures of the devices were formed via the RIE process, by etching all of the layers $(>1.2 \mu \mathrm{m})$ down to the nucleation layer for mesa isolation. After an ohmic etch of $\sim 0.7 \mu \mathrm{m}$, $\mathrm{Ti} / \mathrm{Al} / \mathrm{Ti} / \mathrm{Au}(100 \AA / 1,000 \AA / 100 \AA / 2,000 \AA)$ metal contacts and Ni/Au $(100 \AA / 1,000 \AA)$ metal contacts were deposited by thermal evaporation and left in acetone for the lift-off process for $\mathrm{N}+$ and $\mathrm{P}+$ ohmic contacts, respectively. The ohmic contacts were annealed at $750^{\circ} \mathrm{C}$ for $60 \mathrm{~s}$. Thereafter, a $240 \mathrm{~nm}$ thick SiO 2 was deposited via plasma enhanced chemical vapor deposition (PECVD) for passivation. Finally, a $\sim 0.3 \mu \mathrm{m}$ thick Ti/Au interconnect metal was deposited and lifted-off in order to connect the n-type and p-type ohmic contact layers to the coplanar waveguide transmission line pads (Fig. 1).

Spectral transmission, current-voltage (I-V), and quantum efficiency (QE) measurements were performed. Icharacterization of the fabricated photodetectors was carried out by using a 4142B electrometer and Keithley 6517A high resistance electrometer with low noise triax cables. QE measurements were performed using a Xenon arc lamp, monochromator, UV-enhanced fiber, and SRS lock-in amplifier. Solar blindness is guaranteed by the cut off wavelength, which is $276 \mathrm{~nm}$. The I-V measurement results in Figure 2 show that the 5V bias dark current of a 200 diameter photodetector was $5 \mathrm{fA}$. This current level corresponds to the background noise floor of the electrometer that was used for the experiments, i.e. the minimum value that the electrometer can measure. The corresponding dark current density was $1.6 \times 10^{-11} \mathrm{~A} / \mathrm{cm}^{2}$. The dark current at $120 \mathrm{~V}$ was $1.6 \mathrm{nA}$. The breakdown voltage of the photodetectors was measured as approximately $250 \mathrm{~V}$. To our knowledge in terms of breakdown voltage and dark current density at $5 \mathrm{~V}$, these values correspond to the best results for AlGaN based solar-blind p-i-n type photodetectors.

Besides these solar-blind AlGaN detectors, a $\mathrm{n}$ eight element array of wavelength sensitive back-illuminated ultraviolet metal-semiconductor-metal photodetectors was demonstrated on an $\mathrm{Al}{ }_{\mathrm{x}} \mathrm{Ga}_{1-\mathrm{x}} \mathrm{N}$ heterostructure. The average of the full-width at half-maximum (FWHM) of the responsivity peaks was $10 \mathrm{~nm}$. Relative response function of consecutive photodetector elements is proposed to determine the wavelength of monochromatic illumination in the 250 $\mathrm{nm}$ to $335 \mathrm{~nm}$ wavelength range. By comparing the measured cut-off wavelengths to published data, the molecular composition of each layer shown in Fig. 3 is determined. The thicknesses of each layer were determined to be in accordance with the design value of $500 \mathrm{~nm}$, within a $5 \%$ error associated with the thickness measurement. The responsivity of each element of the wavelength-sensitive photodetector array is plotted in Fig. 4 for the $250 \mathrm{~nm}-350$ nm spectral range. 


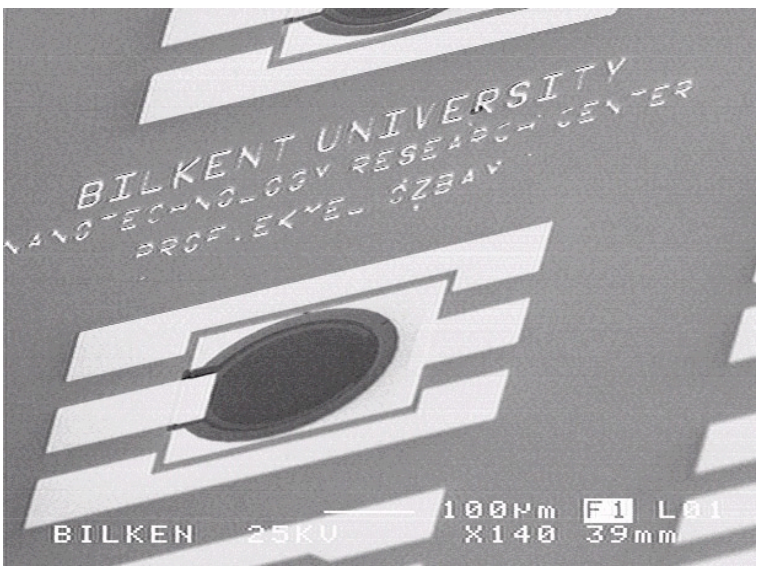

Fig. 1. SEM image of 200 micron diameter $f$ abricated device

\begin{tabular}{|c|}
\hline $\mathrm{Al}_{0.08} \mathrm{Ga}_{0.92} \mathrm{~N} \quad(500 \mathrm{~nm})$ \\
\hline $\mathrm{Al}_{0.11} \mathrm{Ga}_{0.89} \mathrm{~N} \quad(500 \mathrm{~nm})$ \\
\hline $\mathrm{Al}_{0.16} \mathrm{Ga}_{0.84} \mathrm{~N} \quad(500 \mathrm{~nm})$ \\
\hline $\mathrm{Al}_{0.20} \mathrm{Ga}_{0.80} \mathrm{~N} \quad(500 \mathrm{~nm})$ \\
\hline $\mathrm{Al}_{0.25} \mathrm{Ga}_{0.75} \mathrm{~N} \quad(500 \mathrm{~nm})$ \\
\hline $\mathrm{Al}_{0.31} \mathrm{Ga}_{0.69} \mathrm{~N} \quad(500 \mathrm{~nm})$ \\
\hline $\mathrm{Al}_{0.40} \mathrm{Ga}_{0.60} \mathrm{~N} \quad(500 \mathrm{~nm})$ \\
\hline $\mathrm{Al}_{0.45} \mathrm{Ga}_{0.55} \mathrm{~N} \quad(500 \mathrm{~nm})$ \\
\hline $\mathrm{Al}_{0.50} \mathrm{Ga}_{0.60} \mathrm{~N} \quad(500 \mathrm{~nm})$ \\
\hline Buffer AIN $(150 \mathrm{~nm})$ \\
\hline Sapphire \\
\hline
\end{tabular}

Fig. 3. Epi -layer structure used to study wavelen gth sensitive UV photodetectors.

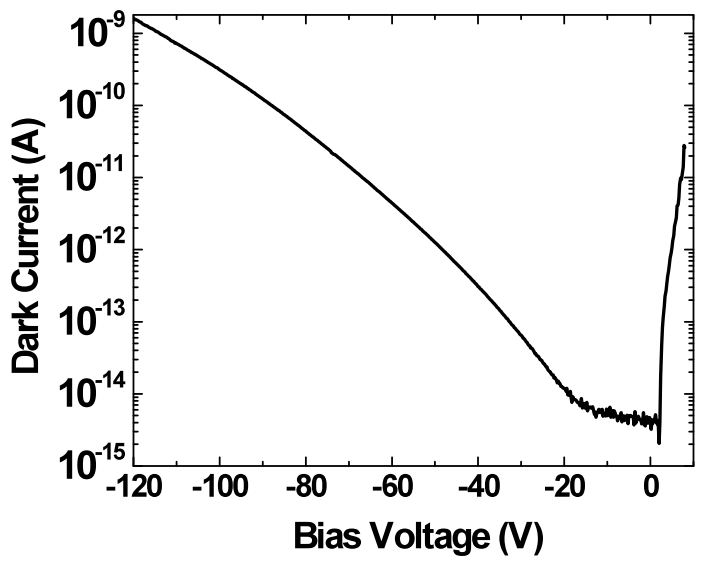

Fig. 2. Dark current of a $200 \mu$ m diameter AlGaN p -i-n photodetector.

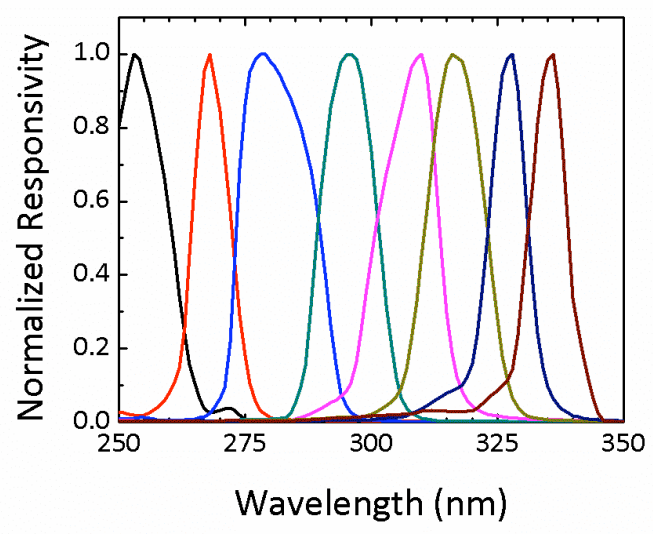

Fig. 4 . Normalized responsivity of wavelength sensitive monolithic stack of MSM photodetectors.

\section{References}

[1] M. Razeghi, and A. Rogalsky, J. Appl. Phys., 79, 7433 (1996).

[2] E. Monroy, F. Omnes, and F. Calle, Semicond. Sci. Technol., 18, R33 (2003).

[3] M.A. Khan, M.Shatalov, H.P. Maruska, H.M. Wang, and E.Kuokstis, Jpn. J. Appl. Phys. P1, 44, 7191 (2005).

[4] E. Monroy, F. Calle, E. Munoz, and F. Omnes, Appl. Phys. Lett., 74, 3401 (1999).

[5] T. Li, D. J. H. Lambert, A. L. Beck, C. J. Collins, B. Yang, J. M. M. Wong, U. Chowdhury, R.D. Dupuis, and J. C. Campbell, Electron. Lett. 36, 1581 (2000).

[6] N. Biyikli, I. Kimukin, O. Aytur, M. Gökkavas, M.S. Unlu, and E. Ozbay, Appl. Phys. Lett., 79, 2838 (2001).

[7] C. J. Collins, U. Chowdhury, M. M. Wong, B. Yang, A. L. Beck, R. D. Dupuis, and J. C. Campbell, Appl. Phys. Lett., 80, 3754 (2002).

[8] T. Tut, B. Butun, M. Gökkavas, and E. Ozbay, Photonics and Nanostructures-Fundamentals and Applications , 5, 140 (2007).

[9] M.B. Reine, P.W. Norton, R. Starr, M.H. Weiler, M. Kestigian, B.L. Musicant, P. Mitra, T. Schimert, F.C. Case, I.B. Bhat, H. Ehsani, V. Rao, J. Electron. Mater., 24, 669 (1995).

[10] M. Gökkavas, S. Butun, H.B. Yu, T. Tut, B. Butun, and E. Ozbay, App. Phys. Lett., 89, 143503 (2006).

[11] S. Butun, M. Gökkavas, H.B. Yu, and E. Ozbay, App. Phys. Lett., 89, 073503 (2006).

[12] S. Butun, T. Tut, M. Gökkavas, H.B. Yu, and E. Ozbay, App. Phys. Lett., 88, 123503 (2006). 